\title{
Reconstruction of Ob River, Russia, discharge from ring widths of floodplain trees
}

Leonid I. Agafonov ${ }^{\mathrm{a}}$, David M. Meko ${ }^{\mathrm{b}}$ and Irina P. Panyushkina ${ }^{\mathrm{b}}$

${ }^{\text {a }}$ Institute of Plant and Animal Ecology UB RAS

202 Marta 8th St., Yekaterinburg, 620144, Russia

lagafonov@ipae.uran.ru

${ }^{\mathrm{b}}$ Laboratory of Tree-Ring Research, University of Arizona

1215 E. Lowell St., Tucson, AZ 85721, USA

dmeko@LTRR.arizona.edu

ipanyush@email.arizona.edu

Corresponding Author: David M. Meko

\begin{abstract}
The Ob is the third largest Eurasian river supplying heat and freshwater to the Arctic Ocean.

These inputs influence water salinity, ice coverage, ocean temperatures and ocean circulation, and ultimately the global climate system. Variability of Ob River flow on long time scales is poorly understood, however, because gaged flow records are short. Eleven tree-ring width chronologies of Pinus sibirica and Larix sibirica are developed from the floodplain of the Lower Ob River, analyzed for hydroclimatic signal and applied as predictors in a regression model to reconstruct 8month average (December-July) discharge of the Ob River at Salekhard over the interval 17052012 (308 yrs). Correlation analysis suggests the signal for discharge comes through air temperature: high discharge and floodplain water levels favor cool growing-season air temperature, which limits tree growth for the sampled species at these high latitudes. The
\end{abstract}


reconstruction model $\left(R^{2}=0.31,1937-2009\right.$ calibration period) is strongly supported by crossvalidation and analysis of residuals. Correlation of observed with reconstructed discharge improves with smoothing. The long-term reconstruction correlates significantly with a previous Ob River reconstruction from ring widths of trees outside the Ob River floodplain and extends that record by another century. Results suggest that large multi-decadal swings in discharge have occurred at irregular intervals, that variations in the $20^{\text {th }}$ and $21^{\text {st }}$ centuries have been within the envelope of natural variability of the past 3 centuries, and that discharge data for 1937-2009 underestimate both the variability and persistence of discharge in the last 3 centuries. The reconstruction gives ecologists, climatologists and water resource planners a long-term context for assessment of climate change impacts.

\section{Highlights}

- Tree-ring data from the Lower Ob River Basin has a signal for river discharge

- Low growth reflects cool air temperatures, driven partly by high water levels

- December-July discharge was reconstructed from tree rings back to 1705

- Extremes in discharge on the Ob occurred prior to the start of the gaged record

- Reconstructed Ob River discharge is characterized by large multi-decadal swings

Keywords: Dendrohydrology; Ob River; Streamflow reconstruction; Tree rings; Arctic Ocean warming; Northern Eurasia river discharge variability

\section{Introduction}

Much attention has been paid to research on river runoff in the context of global climate change (ACIA, 2005; Serreze et al., 2006; IPCC, 2013; Harding et al., 2011). Such attention is deserved because river runoff is an important component of the hydrological cycle and a main constituent of 
the climate system. Terrestrial water-cycle processes regulating evaporation, runoff and changes in the hydrological cycle are directly linked with atmospheric processes (Chahine, 1992; Rawlins, 2010; Shiklomanov et al., 2011; Polyakov et.al., 2013). The terrestrial hydrological cycle is especially important for the Arctic Ocean "where the volume of sea water is relatively small as compared with the volume of river water entering the ocean” (Shiklomanov and Shiklomanov, 2003). Changes in the terrestrial hydrologic budget of the Northern Hemisphere influence the freshwater inflow to the Arctic Ocean (Peterson et al., 2002, 2006; McClelland et al., 2004; Mauritzen, 2012), which in turn affects ocean salinity, sea-ice coverage, and ocean circulation (Aagaard and Carmack, 1989; Ployakov et al., 2013). Annual river discharge comprises 38\% of the freshwater input to the Arctic Ocean (Serreze et al., 2006), and the export of river freshwater to the Arctic Ocean is about $11 \%$ of the global river discharge (Shiklomanov, 2000).

The degree to which discharge of Arctic rivers is affected by climate change is as yet speculative. Peterson et al. (2006) suggest that the river discharge correlates with changes in both the North Atlantic Oscillation and global mean surface air temperature. They note the average annual rate of river discharge from 6 major Eurasian rivers increased at about $2.0 \pm 0.7 \mathrm{~km}^{3} \mathrm{yr}^{-1}$ from 1936 to 1999 and is greater now (about $128 \mathrm{~km}^{3} \mathrm{yr}^{-1}$ ) than it was in the 1930s (Peterson et al., 2002). The most obvious change in northern Eurasia river discharge is an increase in winter flows (Peterson et al., 2002; Shiklomanov and Shiklomanov, 2003; Yang et al., 2004; Rennermalm et al., 2010).

A credible reason for this mode of change is the impact of dams built for generation of hydroelectric power (McClelland et al., 2004; Magritskii, 2008; Adam et al., 2007). Another possible reason is a rise of air temperature in autumn over the basins and an associated delayed establishment of snow cover (Barnett et al., 2005; Agafonov, 2010). One point of view is that recent increasing river discharge in Eurasia is a fluctuation rather than a change. Early studies identified cycles at wavelength 25-30 years in river discharge and lake levels over Inner Eurasia (Shnitnikov, 1969). More recently researchers argue that the "interannual variation of the total 
river runoff into the Arctic Ocean and the total runoff of the Asian rivers into the ocean over the historical period of observations is statistically homogeneous with a clearly defined quasiperiodicity” (Simonov and Khristoforov, 2005).

Understanding the discharge variability of rivers flowing into the Arctic Ocean is important not only to address to the impact of climate change, but also to improve water and natural resources management across the drainage basins. Tree-ring records are a valuable proxy for extending the historical observations of runoff (Meko and Woodhouse, 2011). MacDonald et al. (2007) applied the Eurasian network of tree-ring sites to reconstruct 200 years of regional variability in discharge of seven major Eurasian rivers flowing into the Arctic Ocean. The reconstructions showed no significant upward trend in annual discharge during the $20^{\text {th }}$ Century, and suggested that discharge variations during that century were within bounds of the natural variability at longer time scales. Among the rivers reconstructed by MacDonald et al. (2007) was the Ob, whose annual discharge accounts $8 \%$ of the total freshwater inflow to the Arctic (Lammers et al., 2001). In this study we suggest a new approach to reconstruct Ob River discharge that exploits the temperature sensitivity of tree rings of floodplain trees. Tree growth of conifers along the Lower $\mathrm{Ob}$ is strongly limited by air temperature and reflects water level fluctuations. High water levels and floods cool down surface air temperature over the floodplain and reduce radial growth of trees (Agafonov and Mazepa, 2001). Conversely, low water levels link to warmer air temperatures and higher tree-ring growth. We sampled tree rings of Pinus sibirica and Larix sibirica along the Lower $\mathrm{Ob}$ to test the hydrological signal in ring width using linear regression and the gaged discharge at Salekhard, near the mouth of the Ob. The goal was to reconstruct $\mathrm{Ob}$ River discharge for a period greater than 200 years and to evaluate short-term and long-term variability of discharge in the context of previous dendrohydrological studies.

\section{Study Area}


The Ob River and its major tributary, the Irtysh, (combined length 3,650 km, drainage area 2,972,497 $\mathrm{km}^{2}$ ) are located in western Siberia (Fig. 1). From snow-dominated headwaters in the Altay-Sayan Mountain belt of Inner Asia, the Ob flows into the Arctic Ocean through the Kara Sea. The Ob River has the largest watershed of all Arctic rivers and the third largest runoff after the Yenisey and Lena Rivers (SWC, 1984). Mean annual discharge of the Ob at Salekhard, $70 \mathrm{~km}$ from the mouth of the river, is $12,475 \mathrm{~m}^{3} / \mathrm{s}$ or $394 \mathrm{~km}^{3} / \mathrm{yr}$ (ArcticRIMS). Approximately $70 \%$ of the Ob’s annual discharge occurs during the ice-free period from May to October, and $80 \%$ of the annual runoff originates southward of $61^{0} \mathrm{~N}$ latitude, which is about $1150 \mathrm{~km}$ from the Ob estuary (SWC, 1984). The hydrological regime of the Ob River is dominated by snowmelt, with peak flows in June-July (Fig. 2). Summer precipitation contributes to the high August runoff, which varies greatly from one year to another. Precipitation in the Ob River catchment is driven by disturbances in the westerlies, and the hydroclimatic regime is influenced by interactions between the Siberian High and westerly jet stream over the Eurasian continent (Panagiotopoulos et al., 2005).

Several major hydropower dams and reservoirs are located above the confluence of the $\mathrm{Ob}$ and Irtysh (McClelland et al., 2004). Dam and reservoir operations have changed the seasonality of river flows in the Ob Basin since the 1970s. Winter flows have increased and summer flows have decreased (Yang et al., 2004). Water use by agriculture and the metal industry in the relatively densely populated Middle Ob region has also impacted the seasonal variability of flows south of the confluence with the Irtysh River (Yang et al., 2004). The Lower Ob River - north of the confluence - has neither major dams and reservoirs nor high-density population.

This study sampled tree rings from trees growing on the floodplain along a $120 \mathrm{~km}$ reach of the Lower Ob River (Fig. 1). The Lower Ob River floodplain covers area of about $20 \times 10^{3} \mathrm{~km}^{2}$. The flat topography of the West Siberian Plains accommodates a floodplain with a width ranging from $20 \mathrm{~km}$ to $60 \mathrm{~km}$. This area is prone to extensive summer inundation that can last for several months. During episodes of large inundation the Lower Ob floodplain is capable of storing more 
than $100 \mathrm{~km}^{3}$ of water (Antipov and Bachurin, 1989). Such storage can be expected to modify air surface temperatures as energy from radiation is directed to latent heat rather than sensible heat.

\section{[FIG. 1, $2 \rightarrow$ HERE]}

\section{Data and Methods}

\subsection{Hydroclimatic data}

Monthly data of Ob River discharge for the gage at Salekhard (N 66 32', E 66 $36^{\circ}$ ) was downloaded from the ArcticRIMs database (http://rims.unh.edu). Discharge for the water year (October-September) over the 73 years 1937-2009 is slightly autocorrelated at a lag of 1 year $\left(r_{1}=0.35\right)$, and varies greatly from year to year - from $29 \%$ below the long-term mean to $44 \%$ above the mean (Table 1). Relationships between the tree-ring data and climate were summarized using monthly precipitation and temperature data from the RIHMI database (www.meteo.ru) for stations Muzhi and Oktyabrskoye. A monthly climogram for Muzhi illustrates the strongly continental climate regime along the Low Ob (Fig. 3). Monthly precipitation typically peaks in mid-summer. The growing season, defined by monthly mean temperatures above $0{ }^{0} \mathrm{C}$, is MaySeptember. This monthly growing season can be considerably extended in some years, as evidence by occasional means above freezing for April and October (Fig. 3).

\section{[FIG 3, TABLE $1 \rightarrow$ HERE]}

\subsection{Tree-ring data}

Two cores per tree (13-47 trees) were sampled from six sites of Larix sibirica and five sites of Pinus sibirica on the floodplain of the Lower Ob (Fig. 1, Table 2). The sampled trees are from riverbanks less than $400 \mathrm{~m}$ away from the main channel or from terraces no more than $30 \mathrm{~m}$ above the water level (Table S1). While some sites were first sampled as early as 1990, all were updated by the authors during major sampling campaigns in 2012-2014. Samples were prepared and rings dated and measured by conventional methods (Stokes and Smiley, 1996). Cross-dating and measurements were checked with program COFECHA (Holmes, 1983) and site chronologies were generated with program ARSTAN (Cook et al., 2007). Each chronology was prepared with the 
same protocol: 1) fit each ring-width series with a cubic smoothing spline with a frequency response of 0.5 at a wavelength 2/3 the sample length (Cook and Peters, 1981), 2) remove trend by taking the ratio of measured widths to the fitted line, 3) combine index series for individual cores using a bi-weight robust mean (Cook and Kairiukstis 1990), and 4) variance-stabilize the resulting site chronology to adjust for time-varying sample size (Osborn et al., 1997). Adequacy of the sample size to capture the population signal for tree-ring variation at the site was assessed with the expressed population signal (EPS; Wigley et al., 1984).

\section{[TABLE $2 \rightarrow$ HERE]}

\subsection{Reconstruction and analysis}

Site chronologies were transformed by principal components analysis (PCA; Mardia et al., 1979) into orthogonal variables for possible use as predictors in reconstruction models. This approach has been widely used in dendrohydrologic reconstruction to reduce redundancy in treering data (e.g., Meko et al., 2001; Woodhouse et al., 2006; Meko et al., 2007). PCA was run on the correlation matrix of the 11 site chronologies for their 1705-2012 common period, and the important components were identified using an eigenvalue-of-1 rule and scree plot (Mardia et al., 1979).

The seasonal climatic signal in tree-ring series was identified with program Seascorr (Meko et al., 2011), which examines correlations and partial correlations between a tree-ring series and climatic data aggregated over variable-length seasons.

The season for discharge reconstruction was selected by stepwise regression (Weisberg, 1985) of Ob River at Salekhard discharge (monthly or seasonal), 1937-2009, on the tree-ring PC time series. We used gaged discharge, rather than discharge adjusted for upstream anthropogenic influences (dams, changes in water usage, etc.) because our sampled trees are downstream of the reservoirs. Variations in air temperature directly influencing the growth of the sampled trees according to our conceptual model are driven by variations in actual rather than adjusted flows. 
Trial regressions were run, each time varying the ending month and length of season for average discharge. Stepwise entry of predictors in model trials was guided by $p$-to-enter and $p$-to-remove thresholds of 0.05 and 0.10 (Weisberg, 1985). Cross-validation (Michaelsen, 1987) was done at each step as a safeguard against model over-fitting, such that an additional step in the stepwise procedure was accepted only if that step yielded an increase in skill as measured by the reductionof-error statistic (RE; Cook and Kairiukstis, 1990).

The regression model for the optimal season, as identified above, was then re-calibrated, subjected to analysis of residuals to identify possible violations of regression assumptions (Weisberg, 1985), and applied to the extended record of tree-ring PC scores to generate a longterm reconstruction of discharge, 1705-2012. A confidence interval around the reconstruction was estimated from the cross-validation mean-square error of the regression and the assumption that the reconstruction errors are normally distributed. Extrapolations, or reconstructed values for years in which the predictors are outside the multivariate space they occupy in the calibration period, were identified by the ellipsoid method described by Weisberg (1985, p. 236).

Linear relationships between pairs of time series were described by the Pearson correlation coefficient (Haan, 2002), with significance level adjusted as needed to account for autocorrelation in time series as suggested by Dawdy and Matalas (1964). Low frequency variations in time series were extracted by Gaussian filters designed with specific cutoff frequencies (Mitchell et al., 1966). “Discrete” peak or troughs (highs or lows) in smoothed series were defined as those separated by more than the width of the corresponding Gaussian filter used for smoothing. Weights of filters used in this paper are listed in the Supplementary Material.

Simple linear regression (variable against time) was applied to test for trend in time series; a slope coefficient differing from zero at a specified $\alpha$-level by a $t$-test was accepted as evidence of significant linear trend. Periodicity was tested by the smoothed periodogram method of spectral analysis (Bloomberg, 2000). For an appropriate "simultaneous" confidence interval on the 
spectrum, the theoretical interval based on a chi-square distribution was widened to account for multiple tests using Bernoulli's inequalities (Snedecor and Cochran, 1989, p. 116).

\section{Results and Discussion}

\subsection{Hydrologic signal in tree rings}

PCA on the 11 standard tree-ring chronologies, 1705-2012, indicated that the primary mode of variation is same-sign growth departure at all sites. This common-growth mode is summarized by PC1, which accounts for 54\% of the tree-ring variance (Table 3). While eigenvalues exceed 1.0 for only the first two PCs, a scree plot suggests four PCs (85\% cumulative variance) should be retained for subsequent analysis (Fig. S2). PC2 is a species contrast, with opposite-sign loading on larch and pine. PC3 is a regional contrast, with negative loadings on just the southernmost 3 sites. PC4 is more complex than the other PCs, but its main contrast is a far-north larch site (LV, \#1 in Fig. 1) with a far-south pine site (KK, \#10 in Fig. 1).

Seascorr results for tree-ring PC1 with the Muzhi monthly and seasonal climatic observations show that tree-growth is positively correlated with air temperature in the warm season (Fig. 4, top). Partial correlations (controlling for temperature) show additional positive contribution to growth from high precipitation in June (Fig. 4, bottom). Previous studies have indicated the importance of a few weeks in June and July to cambial activity and tree-ring formation at such high-latitude locations in Siberia (Vaganov et al., 2006; Rossi et al., 2008). The positive temperature correlation is consistent with other studies showing that tree-growth of the sampled species at this high-latitude location is limited by low temperature (Vaganov et al., 1996). We hypothesize that the positive correlation of growth to June precipitation reflects the importance of soil moisture in facilitating or hindering the transfer of heat from the air to the root system of the trees: high June precipitation and a wet soil profile favor heat transfer into the soil when June air temperature is high. 


\section{[TABLE $3 \rightarrow$ HERE]}

The relationship between air temperature and tree-growth is critical to the reconstruction of Ob River discharge from floodplain trees along the Lower Ob. Ob River discharge at Salekhard closely tracks Ob water levels throughout the Lower Ob River Basin (Agafonov and Mazepa, 2001), and water level variations from year to year are negatively correlated with air temperatures at the tree-ring sites (Table 2). Relationships can be summarized with the discharge record at Salekhard and climate data from Muzhi. Positive correlation between these variables through the ice-free cool-season months reaches peak significance $(\mathrm{p}<0.0001)$ in May, and then switches abruptly to a weakly significant $(\mathrm{p}<0.05)$ negative correlation in June (Fig. 5). This pattern of correlation is consistent with the water from the south warming the normally cool air during the cooler months of the year and moderating the warm air temperature during the late spring and early summer. As tree-growth for the species used here does not normally begin until June (Agafonov and Gurskaya, 2013), the dominant indirect river influence on tree growth is to reduce growth in high-flow years and increase growth in low-flow years.

\section{[FIG. 4, FIG $5 \rightarrow$ HERE]}

Stepwise regression of discharge at Salekhard on PCs 1-4 of tree rings for various seasonal groupings of discharge ending with July of the growth year indicate maximum strength of signal $\left(R^{2}=0.31, \mathrm{~F}=15.6, \mathrm{p}<1 \mathrm{E}-5\right)$ for an 8-month window beginning in December of the preceding the growth year (Fig. 6). The signal, while much weaker than that for some basins in temperate latitudes, such as the Sacramento (Meko et al., 2001) and Colorado (Woodhouse et al., 2006), was judged strong enough to justify a reconstruction effort.

\section{[FIG. 6 - $\rightarrow$ HERE]}

\subsection{Streamflow reconstruction}

The reconstructed model selected from the exploratory stepwise regression just described and calibrated on the years 1937-2009, is 


$$
\hat{y}=\hat{a}+\hat{b}_{1} x_{1}+\hat{b}_{2} x_{2}
$$

where $x_{1}$ and $x_{2}$ are scores of PCs 1 and 4 , respectively, of the 11 tree-ring chronologies; $\hat{a}, \hat{b}_{1}$, and $\hat{b}_{2}$ are the estimated regression constant and coefficients; and $\hat{y}$ is the reconstructed discharge (December-July average). Positive cross-validation RE indicates skill of reconstruction using data not used in calibration (Table 4). No appreciable gain in RE resulted from letting additional PCs enter as predictors into the model. An analysis of residuals indicated no obvious problems, such as non-normality of residuals or systematic dependence of variance of residuals on fitted (reconstructed) discharge (Fig. S3, S4). In particular, the null hypothesis of non-autocorrelated residuals could not be rejected based on the Durbin-Watson statistic (Table 4). For a long-term reconstruction, the PC scores (PCs 1 and 4) for the period 1705-2012 were substituted into the reconstruction equation. A 1705 start year was supported by the statistical summary of the treering data, which indicated that the EPS threshold of 0.85 was reached before 1705 at most sites, and as early as 1555 at one site (Table 2).

\section{[TABLE $4 \rightarrow$ HERE]}

The reconstruction tracks observed discharge at annual and decadal time scales during the calibration period (Fig. 7). As expected with such a low regression $R^{2}$, large discrepancies occur in some years - e.g., the failure to identify low discharge in 1954 and 1967. Reconstruction bias in discharge statistics for the calibration period includes underestimation of lag-1 autocorrelation and large underestimation of spread - a necessary consequence of regression $R^{2}<<1$ (Table 5). The bias dictates using the reconstructed discharge alone (i.e., rows 2 vs 3 in Table 5) for a long-term context of short-period discharge statistics. The reconstruction viewed in this way suggests that the snapshot for1937-2009 underestimates both the variability (standard deviation and range) and lag1 autocorrelation of discharge of the past 300 years.

\section{[TABLE $5 \rightarrow$ HERE]}




\subsection{Analysis of reconstruction}

Reconstructed discharge, 1705-2012, varies greatly at high and low frequencies, and has its high and low extremes before the start of the gaged record, in 1937 (Fig. 8). Uncertainty is summarized by the $50 \%$ confidence interval: the true (unknown) discharge in any given year has a $50 \%$ chance of falling outside the displayed confidence interval. Years flagged as extrapolations in Fig. 8 have additional uncertainty, as the predictors (PC1 and PC4) in those years fall outside an ellipse describing the bivariate domain of the predictors in the calibration period. Eight extrapolations occur in the long-term reconstruction.

\section{[FIG. 7, FIG. 8, TABLE $5 \rightarrow$ HERE]}

While the annual reconstruction leaves $69 \%$ of variance of discharge over the calibration period unexplained, accuracy is improved with smoothing (Fig. 9). For example, the correlation of observed with reconstructed discharge increases from $r=0.55$ for the unsmoothed reconstruction to $r=0.69$ for the reconstruction smoothed with a 10-year Gaussian filter. Accordingly, we assess dry periods and wet periods by lows and highs in the reconstruction after smoothing. The 10-year Gaussian smoothed series is plotted in Fig. 8, while lows and highs the unsmoothed reconstruction and at three levels of smoothing are listed in Table 6. For 10-year smoothing, reconstructed lows in 1727,1829 and 1878 are below the reconstructed extreme calibration period reconstructed low of $1,1769 \mathrm{~m} 3 / \mathrm{s}$, in 1956 . Seven discrete peaks in the 10-yr smoothed series before 1937 are higher than the highest calibration-period peak, in 1978. Multi-decadal periods of relatively low and high variability recur in different parts of the series. Most prominent are two wet intervals in the latter half of the 19th century. Annual and smoothed reconstructions both suggest the gaged period (1937-2009) underestimates the range of natural variability of discharge.

\section{[FIG. 9 HERE, TABLE 6 HERE]]}

While spline detrending as applied here in chronology development would remove any climatic trend at wavelengths on the order of the length of individual measured ring-width series or longer (Cook et al., 1995), shorter trends will be retained in the reconstruction. Trends 
persisting over 2-3 decades are evident in the reconstruction (Fig. 8). Significant trend is found over the 1937-2009 calibration for the gaged discharge, but not for the reconstruction (Fig. 7). As a percentage of the mean per decade this recent trend, with significance in parentheses, is $\Delta Q=1.38 \%(p=0.02)$ for the gaged discharge and $\Delta Q=0.08 \%(p=0.81)$ for the reconstruction. The trend in gaged discharge is consistent with the general tendencies (see Introduction) for the Arctic rivers in Eurasia. The discrepancy in recent trend between gaged and reconstructed discharge is reflected in a significant positive trend in regression residuals of the reconstruction model (Fig. S4). The trend in gaged December-July discharge is driven primarily by trend in winter discharge, when trees are dormant and relatively insensitive to variation in air temperature variations and discharge (Fig. S7).

The time plot of reconstructed discharge in Fig. 8 is characterized by high-amplitude multi-decade swings of potential importance to water and power management on the Ob, as well as to ecology of the basin. Spectral analysis does not, however, support significant periodicity in the annual reconstruction (Fig. S5). No spectral peaks are significant at $\alpha=0.01$, even without widening the confidence interval around the spectrum to account for multiple comparisons. The smooth decadal fluctuations in the reconstructed discharge can be best described as irregular.

Only one previous Ob River reconstruction, by MacDonald et al. (2007) exists for comparison with our new reconstruction. For brevity, we abbreviate the reconstructions here as "M2007" and "A2016". The two reconstructions are independent in that M2007 is based on a large Eurasian network of tree-ring chronologies, none of which are in A2016, and none of which are along the Low Ob River. The conceptual model for M2007 relies on spatial anomalies in tree-ring growth on a continental scale capturing synoptic climatological variability (e.g., ridges, troughs, storm tracks) related to runoff, while our model relies on a local response of trees along the Lower Ob River to air temperature variation specifically driven by water levels on the Ob. The predictand 
for both reconstructions is discharge at Salekhard, but for M2007 is "adjusted" discharge for the water year, and for A2016 is unadjusted discharge averaged for December-July.

Despite the aforementioned differences, the two reconstructions share many features (Fig. 10), and are significantly correlated over their 1800-1990 common period ( $r=0.53, \mathrm{p}<0.001$; Fig. S6). For neither reconstruction are the discharge fluctuations in the 20th century outside the range of natural variability estimated by tree rings. The new reconstruction suggests that this finding could be modified to include the first decade of the 21st century (Fig. 8).

\section{[FIG 10 HERE]}

\section{Conclusions and Perspective}

The main finding of this study is that useful information on long-term variability of Ob River discharge can be obtained from ring widths of conifers growing on banks and fluvial terraces along lower reaches of the river. The discharge signal depends on the combination of temperature sensitivity of tree growth, seasonality of tree-ring formation, and large-scale modification of floodplain air temperatures by inter-annual water-level variations of the river. June precipitation may modulate the tree-growth response to temperature through soil moisture variation during a critical period of ring formation: wet soils facilitate heat transfer and vice versa. A 308-year reconstruction of discharge based on this signal suggests that large, irregular, fluctuations in discharge on decadal and multi-decadal time scales are characteristic of the Ob River, and that recent fluctuations have been exceeded in amplitude by fluctuations before the start of gaged discharge record.

Future studies should attempt to combine the type of discharge signal illustrated here with other tree-ring information for improved accuracy of reconstruction of discharge of the Ob River and possibly of other large northern rivers. That only 31\% of the variance of December-July discharge can be reconstructed from our tree-ring network underscores the fact that tree growth along the Lower $\mathrm{Ob}$ is imperfectly related to air temperature and that air temperature is imperfectly 
related to water level fluctuation of the Ob River. Large-scale tree-ring networks, such as that used by MacDonald et al. (2007) could possibly be used adjust for influence other than Ob water levels on air temperatures in the lower basin. For example such networks might be able to identify episodes of temperature advection during the growth season of the trees due to anomalous positioning of ridges and troughs.

While the sampled trees for this study are from slightly elevated settings not subject to inundation for periods of weeks to months, extensive stands of riparian trees that can tolerate inundation can also be found along the Lower Ob River. Such trees could be investigated for complementary tree-ring information on discharge using ring-width patterns (e.g., Meko et al., 2015) or morphological features of the annual rings (e.g., St. George, 2010; Therrell and Bialecki, 2015).

\section{Acknowledgements}

This work was supported by grants from the CRDF Global Research Partnerships program (\#RUC1-7075-EK-12 and \#FSCX-15-61824-0), and Russian Foundation for Basic Research (\#1304-01964, \#05-04-48298, \#00-05-65041). We acknowledge also the generous assistance in provision of a research vessel and land facilities by the Institute of Plant and Animal Ecology, Ural Branch of Russian Academy of Sciences, in Yekaterinburg and Labytnangi.

\section{Appendix A}

Supplementary data associated with this article can be found in the online version http:/dx.doi.org/XXXXX.

\section{References}

Aagaard, K., Carmack, E.C., 1989. The role of sea ice and other fresh water in the Arctic circulation. J. Geophys. Res. 94 (C10), 14485-141498. 
ACIA, 2005. Arctic Climate Impact Assessment, Cambridge Univ. Press, Cambridge, 1042 pp.

Adam, J.C., Haddeland, I., Su, F., Lettenmaier, D.P., 2007. Simulation of reservoir influences on annual and seasonal streamflow changes for the Lena, Yenisei, and Ob’ rivers. J. Geophys. Res. 112 (D2411), doi:10.1029/2007JD008525.

Agafonov, L. I., Mazepa, V.S., 2001. Runoff of Ob River and summer air temperature in the north of Western Siberia. Proceedings of the Russian Academy of Sciences: Geographic Series (Izvestiya AN. Seriya Geographicheskaya) 1, 82-90.

Agafonov, L.I., 2010. Change of Lower Ob River discharge in the XX century. Proceedings of the Russian Academy of Sciences: Geographic Series. (Izvestiya RAN: Seriya Geographicheskaya) 4, 68-76.

Agafonov, L.I., Gurskaya, M.A., 2013. Influence of the Lower Ob River flow on tree ring growth. Contemporary Problems of Ecology 6 (7), 779-787.

Antipov, A.N., Bachurin, G.B. (Eds), 1989. Landscape and Hydrology of Western Siberia. SB RAN Institute of Geography, Irkutsk, 222 pp.

Barnett, T.P, Adam, J.C., Lettenmaier, D.P., 2005. Potential impacts of a warming climate on water availability in snow-dominated regions. Nature 438, 303-309.

Bloomfield, P., 2000. Fourier Analysis of Time Series: An Introduction, second ed., John Wiley \& Sons, New York, 261 pp. 
Chahine, M.T., 1992. The hydrological cycle and its influence on climate. Nature 359, 374-380.

Cook, E. R., Peters, K., 1981. The smoothing spline: A new approach to standardizing forest interior tree-ring width series for dendroclimatic studies. Tree-Ring Bulletin 41, 45-53.

Cook, E. R., Kairiukstis, L.A. (Eds.), 1990. Methods of Dendrochronology: Applications in the Environmental Sciences. Kluwer Academic Publishers, Dordrecht, 394 pp.

Cook, E.R., Briffa, K. R., Meko, D.M., Funkhouser, G., 1995. The “segment length curse” in long tree-ring chronology development for paleoclimatic studies. The Holocene 5 (2), 229-237.

Cook, E. R., Krusic, P. J., Holmes, R. H., Peters K., 2007. Program ARSTAN, Version 41d, 2007, www.ldeo.columbia.edu/tree-ring-laboratory.

Dawdy, D. R., Matalas, N. C., 1964. Statistical and probability analysis of hydrologic data, part III analysis of variance, covariance and time series, in Handbook of Applied Hydrology: A Compendium of Water-Resources Technology. Ed. V. T. Chow, pp. 8.69-8.90, McGraw-Hill Book Company, New York, 1440 pp.

Haan, C.T., 2002. Statistical Methods in Hydrology (2nd ed.). Iowa State University Press, 496 pp.

Harding, R., Best, M., Blyth, E., Hagemann, S., Kabat, P., Tallaksen, L.M., Warnaars, T., Wiberg, D., Weedon, G.P., van Lanen, G., Ludwig, F., Haddeland, I., 2011. WATCH: Current knowledge of the terrestrial global water cycle. J. Hydrometeorology 12, 1149-1156. 
Holmes, R. L., 1983. Computer-assisted quality control in tree-ring dating and measurement. Tree Ring Bull. 43, 69-78.

IPCC, 2013. Climate change 2013: The physical science basis. In: Stocker T.F., Qin D., Plattner G.-K., Tignor M., Allen S.K., Boschung J., Nauels A., Xia Y., Bex V., Midgley P.M. (Eds.), Contribution of Working Group I to the Fifth Assessment Report of the Intergovernmental Panel on Climate Change. Cambridge University Press, Cambridge, United Kingdom and New York, USA, 1535 pp.

Lammers, R.B., Shiklomanov, A.I,, Vörösmarty, C.J, Fekete, B.M., Peterson, B.J., 2001. Assessment of contemporary Arctic river runoff based on observational discharge records. J. Geophys. Res. 106 3321-34.

MacDonald, G. M., Kremenetski, K. V., Smith, L. C., Hidalgo, H. G., 2007. Recent Eurasian river discharge to the Arctic Ocean in the context of longer-term dendrohydrological records. J. Geophys. Res-Biogeo 112 (G4), doi:10.1029/2006JG000333.

Magritskii, D. V., 2008. Anthropogenic impact on the runoff of Russian rivers emptying into the Arctic Ocean. Water Resources 35 (1), 1-14 [original Russian Text (C D.V. Magritskii, 2008, published in Vodnye Resursy, 2008, Vol. 35, No. 1, pp. 3-16].

Mardia, K., Kent, J., Bibby, J., 1979. Multivariate Analysis. Academic Press, London, 518 pp.

Mauritzen, C., 2012. Arctic freshwater. Nature, Geoscience 5, 163-165. 
McClelland, J.W., Holmes, R.M., Peterson, B.J., Stieglitz M., 2004. Increasing river discharge in the Eurasian Arctic: Consideration of dams, permafrost thaw, and fires as potential agents of change. J. of Geophysical Research 109, D18102, doi:10.1029/2004JD004583.

Meko, D. M., Therrell, M. D., Baisan, C. H., Hughes, M. K., 2001. Sacramento River flow reconstructed to A.D. 869 from tree rings. J. Am. Water Resour. Assoc. 37 (4), 1029-1040.

Meko, D. M., Woodhouse, C. A., Baisan, C. A., Knight, T., Lukas, J. J., Hughes, M. K., Salzer, M. W., 2007. Medieval drought in the Upper Colorado River Basin. Geophys. Res. Lett. 34 (L10705), 10.1029/2007GL029,988.

Meko, D. M., Touchan, R., Anchukaitis, K. A., 2011. Seascorr: a MATLAB program for identifying the seasonal climate signal in an annual tree-ring time series. Computers \& Geosciences 37, 1234-1241.

Meko, D.M., Woodhouse, C. A., 2011. Application of streamflow reconstruction to water resources management. In: Dendroclimatology. Progress and Prospects, Developments in Paleoenvironmental Research 11, (Eds.) M. K. Hughes, T. W. Swetnam, and H. F. Diaz. Springer, Netherlands, pp. 231-261.

Meko, D. M., Friedman, J. M., Touchan, R., Edmondson, J. R., Griffin, E. R., Scott J. A, 2015. Alternative standardization approaches to improving streamflow reconstructions with ring-width indices of riparian trees. The Holocene 25 (7), 1093-1101, doi:10.1177/0959683615580181.

Michaelsen, J., 1987. Cross-validation in statistical climate forecast models. J. Clim. Appl. Meteor. 26, 1589-1600. 
Mitchell, J. M. Jr, Dzerdzeevskii, B., Flohn, H., Hofmeyr, W. L., Lamb, H. H., Rao, K. N., Walléen, C. C., 1966. Climatic change. Technical Note 79, Report of a working group of the Commission for Climatology 195 TP 100, WMO, Geneva, Switzerland, 81 pp.

Osborn, T. J., Briffa, K. R., Jones, P. D., 1997. Adjusting variance for sample-size in tree-ring chronologies and other regional mean time series. Dendrochronologia 15, 89-99.

Panagiotopoulos, F., Shahgedanova, M., Hannachi, A., Stephenson D., 2005. Observed trends and teleconnections of the Siberian High. J. of Climate 18, 1411-1422.

Peterson, B.J., Holmes, R.M., McClelland, J.W., Vörösmarty, C.J., Lammers, R.B., Shiklomanov, A.I., Shiklomanov, I.A., Rahmstorf S., 2002. Increasing river discharge to the Arctic Ocean. Science 298, 2171-2173, doi:10.1126/science.

Peterson, B.J., McClelland, J.W., Curry, R. Holmes, R.M., Walsh, J.E, Aagaard, K., 2006. Trajectory shifts in the Arctic and Subarctic freshwater cycle. Science 313, 1061-1066.

Polyakov, I.V., Bhatt, U.S., Walsh J.E., EP Abrahamsen E.R., Pnyushkov A.V., Wassmann P.F., 2013. Recent oceanic changes in the Arctic in the context of long-term observations. Ecological Applications 23 (8), 1745-1764.

Rawlins, M.A., Steele, M., Holland, M.M., 2010. Analysis of the Arctic system for freshwater cycle intensification: observations and expectations. J. of Climate 23, 5715-5737. 
Rennermalm, A.K., Wood, E.F., Troy, T.J., 2010. Observed changes in pan-arctic cold-season minimum monthly river discharge. Clim. Dyn. 35, 923-939.

Rossi, S., Deslauriers, A, Griçar, J., Seo, J.-W., Rathgeber, C.B.K., Anfodillo, T., Morin, H., Levanic, T., Oven, P., Jalkanen, R., 2008. Critical temperatures for xylogenesis in conifers of cold climates. Global Ecology and Biogeography 17, 696-707.

Serreze, M.C., Barrett, A.P., Slater, A.G., Woodgate, R.A., Aagaard, K., Lammers, R.B., Steele, M., Moritz, R., Meredith, M., Lee, C.M., 2006. The large-scale freshwater cycle of the Arctic. J. Geophys. Res. 111, C11010, doi:10.1029/2005JC003424.

Shiklomanov, I.A., 2000. Appraisal and assessment of world water resources. Water International 25 (1), 11-32.

Shiklomanov, A.I., Shiklomanov, I. A., 2003. Climatic change and the dynamics of river runoff into the Arctic Ocean. Water Resources 30 (6), 593-601.

Shiklomanov, A.I, Bohn, T.J., Lettenmaier, D.P., Lammers, R.B., Romanov, P., Rawlins, M.A., Adam, J.C., 2011. Interactions between land cover/use change and hydrology. In: Gutman G., Reissell A. (Eds.), Eurasian Arctic Land Cover and Land Use in a Changing Climate. Springer, Dordrecht.

Shnitnikov, A. V., 1968. Multidecadal Variability of Surface Water. Nauka, Leningrad, 246 pp.

Simonov, Yu. A., Khristoforov, A.V., 2005. Analysis of many-year variations of runoff in river runoff into the Arctic Ocean. Water Resources 32 (6), 587-593. 
Snedecor, G.W., Cochran, W.G., 1989. Statistic Methods ( $8^{\text {th }}$ ed.). Iowa State University Press, 503 pp.

SWC, 1984. State Water Cadastre. Data on Hydrological Regime and Water Resources. Vol.1. Issue 10, Gidrometeoizdat, Leningrad, 320 pp.

St. George, S., 2010. Tree rings as paleoflood and paleostage indicators, in Tree-Ring Reconstructions in Natural Hazards Research: A State-of-the-art Advances in Global Change Research Series, edited by Stoffel, M., Bollschweiler, M., Butler, D. R., Luckman, B. H, pp. 233-240, Springer, New York.

Stokes, M. A., Smiley, T. L., 1996. An Introduction to Tree-Ring Dating. University of Arizona Press, Tucson, (originally published 1968, University of Chicago Press), 73 pp.

Therrell, M. D., Bialecki, M. B., 2015. A multi-century tree-ring record of spring flooding on the Mississippi River. J. Hydrol., 529, 490-498.

Vaganov, E.A., Shiyatov, S.G., Mazepa, V.S., 1996. Dendroclimatic Studies in the Ural-Siberian Subarctic. Nauka, Novosibirsk, 244 pp.

Vaganov, E.A., Hughes, M.K., Shashkin, A.V., 2006. Growth Dynamics of Conifer Tree Rings: Images of Past and Future Environments. Springer-Verlag, Berlin, Heidelberg, 343 pp.

Weisberg, S., 1985. Applied Linear Regression (2nd ed.). John Wiley, New York, 324 pp. 
Wigley, T. M. L., Briffa, K. R., Jones, P. D., 1984. On the average value of correlated time series, with applications in dendroclimatology and hydrometeorology. J. Clim. Appl. Meteor. 23, 201213.

Woodhouse, C. A., Gray, S. T., Meko, D. M., 2006. Updated streamflow reconstructions for the Upper Colorado River Basin, Water Resour. Res. 42 (W05415), doi:10.1029/2005WR004,455.

Yang, D., Ye, B., Shiklomanov, A., 2004. Discharge characteristics and changes over the Ob River watershed in Siberia. J. of Hydrometeorology 5, 595-610. 
Tables

Table 1. Discharge statistics ${ }^{\mathrm{a}}$ of Ob River at Salekhard, 1936-2009.

\begin{tabular}{lcccccc}
\hline \multicolumn{1}{c}{ Season } & Mean & Median & Std. Dev. & $\mathrm{r}_{1}$ & Min \% & Max \% \\
\hline June & 32887 & 33584 & 3450 & 0.17 & 65 & 128 \\
October & 10373 & 10060 & 2238 & 0 & 58 & 193 \\
Water Year & 12769 & 12683 & 12683 & 0.35 & 71 & 144 \\
December-July & 12545 & 12492 & 12492 & 0.23 & 76 & 122 \\
\hline
\end{tabular}

\footnotetext{
${ }^{\mathrm{a}}$ Mean, median and standard deviation in $\mathrm{m}^{3} / \mathrm{sec}$; lag-1 autocorrelation $\left(\mathrm{r}_{1}\right)$, and minimum and maximum values as percentage of mean.
} 
Table 2. Tree-ring site locations and statistics.

\begin{tabular}{ccccccc}
\hline$\#$ & $\begin{array}{c}\text { Site } \\
\text { ID }^{\mathrm{a}}\end{array}$ & N Lat. & E Lon. & $\begin{array}{c}\text { Sample } \\
\text { Size } \\
\mathrm{N}_{\mathrm{T}} \mathrm{N}_{\mathrm{c}}\end{array}$ & $\begin{array}{c}\text { Span } \\
\& \\
\text { Critical Year }^{\mathrm{b}}\end{array}$ & $\begin{array}{c}\text { Ob River } \\
\text { Corr. }^{\mathrm{d}}\end{array}$ \\
\hline 1 & LV & $66^{0} 05$ & $65^{0} 41$ & $35 / 57$ & $1662-2013(1745)$ & -0.41 \\
2 & LL & $65^{0} 41$ & $64^{0} 26$ & $47 / 82$ & $1539-2013(1590 *)$ & -0.39 \\
3 & KV & $65^{0} 35$ & $64^{0} 42$ & $35 / 55$ & $1559-2012\left(1635^{*}\right)$ & -0.44 \\
4 & LPU & $65^{0} 25$ & $64^{0} 35$ & $19 / 25$ & $1671-2013(1695)$ & -0.39 \\
5 & LP & $65^{0} 19$ & $65^{0} 23$ & $34 / 53$ & $1555-2014(1635)$ & -0.45 \\
6 & LLG & $65^{0} 13$ & $65^{0} 21$ & $13 / 18$ & $1665-2014(1720)$ & -0.38 \\
7 & KLG & $65^{0} 13$ & $65^{0} 21$ & $30 / 47$ & $1535-2014(1590)$ & -0.40 \\
8 & KU & $64^{0} 55$ & $64^{0} 55$ & $34 / 56$ & $1420-2013(1555)$ & -0.38 \\
9 & KL & $64^{0} 33$ & $64^{0} 35$ & $44 / 64$ & $1599-2013(1700)$ & -0.40 \\
10 & KK & $64^{0} 25$ & $65^{0} 21$ & $19 / 24$ & $1705-2012(1760)$ & -0.19 \\
11 & LT & $62^{0} 17$ & $65^{0} 56$ & $37 / 49$ & $1566-2014(1600 *)$ & -0.35 \\
\hline
\end{tabular}

aSite ID: first letter L= Larix sibirica (Siberian larch) and K= Pinus sibirica (Siberian pine)

${ }^{\mathrm{b}}$ Number of trees $\left(\mathrm{N}_{\mathrm{T}}\right)$ and number of cores $\left(\mathrm{N}_{\mathrm{c}}\right)$.

${ }^{\mathrm{c}}$ First and last year of data, with first year that EPS $>0.85$ in parentheses; asterisk = first available year for EPS estimate.

${ }^{\mathrm{d}}$ Correlation of tree-ring series with discharge (Dec-July average) over 1937-2009. 
Table 3. Site loadings of first four principal components ${ }^{\mathrm{a}}$ of 11 tree-ring chronologies.

\begin{tabular}{lllll}
\hline Site ID & PC1 & PC2 & PC3 & PC4 \\
\hline LV & 0.2627 & -0.3763 & 0.0436 & 0.5533 \\
LL & 0.3163 & -0.3297 & 0.1764 & -0.1339 \\
KV & 0.3432 & 0.1795 & 0.1744 & 0.1076 \\
LPU & 0.3418 & -0.2325 & 0.0657 & -0.2232 \\
LP & 0.3223 & -0.3052 & 0.051 & -0.0518 \\
LLG & 0.3264 & -0.2387 & 0.0501 & -0.3122 \\
KLG & 0.2928 & 0.3759 & 0.0201 & 0.3115 \\
KU & 0.317 & 0.3158 & 0.0255 & 0.1597 \\
KL & 0.3189 & 0.3388 & -0.0306 & 0.1924 \\
KK & 0.2542 & 0.3837 & -0.0427 & -0.5954 \\
LT & 0.1829 & -0.1012 & -0.9609 & 0.0168
\end{tabular}

${ }^{\text {aPCA was done on the correlation matrix of the 1705-2012 matrix of chronologies; cumulative }}$ percentage of variance explained by 4 PCs is $85 \%$; individual percentages are $54 \%$, 20\%, $7 \%$ and $4 \%$. 
Table 4. Statistics ${ }^{\mathrm{a}}$ of stepwise regression for reconstruction model ${ }^{\mathrm{b}}$.

\begin{tabular}{lccccl}
\hline Step & Predictors & $R^{2}$ & $R^{2}$ adj. & RE & $p_{\text {DW }}$ \\
\hline 1 & PC1 & 0.24 & 0.23 & 0.18 & 0.29 \\
2 & PC1, PC4 & 0.31 & 0.29 & 0.24 & 0.79
\end{tabular}

\footnotetext{
${ }^{a}$ For each step, the regression $R^{2}$, adjusted $R^{2}$, reduction-of-error statistic, and $p$-value of DurbinWatson test for lag-1 autocorrelation of residuals

${ }^{\mathrm{b}}$ Equation of reconstruction model is Q $=12599.8731$-728.9757 PC1 -367.699 PC4, where Q is Dec-July average discharge in $\mathrm{m}^{3} / \mathrm{sec}$, and predictors PC1 and PC4 are z-scores (scaled by 19372009 means and standard deviations) of tree-ring principal components.
} 
Table 5. Statistics ${ }^{\mathrm{a}}$ of observed and reconstructed discharge of Ob River at Salekhard.

\begin{tabular}{lcccccc}
\hline Season & Mean & Median & Std. Dev. & $\mathrm{r}_{1}$ & Min\% Max\% \\
\hline Observed & 12545 & 12492 & 1343 & 0.23 & 76 & 122 \\
Rec: 1937-2009 & 12545 & 12422 & 746 & 0.11 & 87 & 112 \\
Rec: 1705-2012 & 12600 & 12588 & 854 & 0.35 & 81 & 120
\end{tabular}

\footnotetext{
${ }^{a}$ Mean, median and standard deviation in $\mathrm{m}^{3} / \mathrm{sec}$; lag-1 (year) autocorrelation; and maximum and minimum as percentage of observed mean.
} 
Table 6. Lows and highs in annual and smoothed reconstructed discharge.

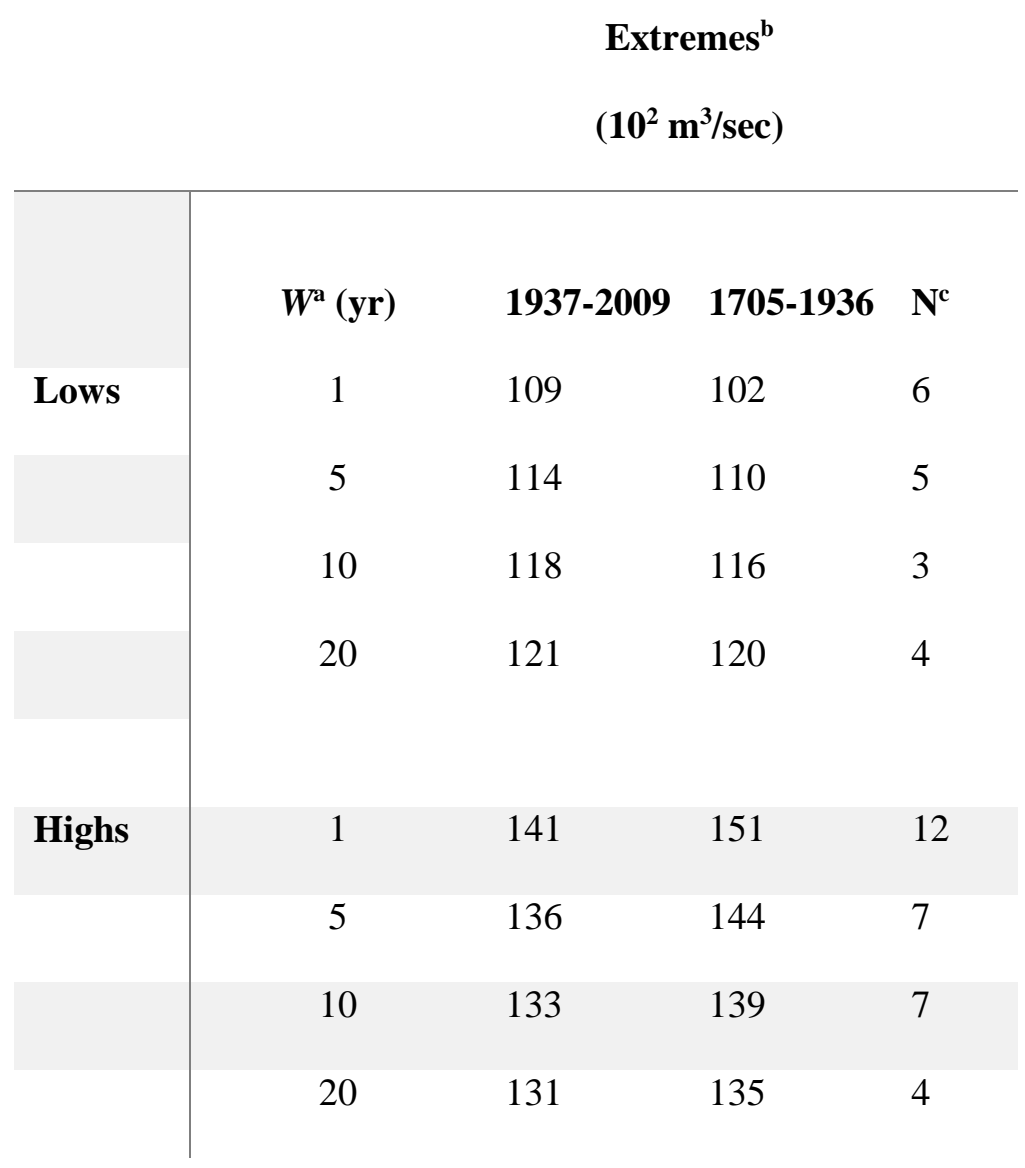

${ }^{\mathrm{b}} \mathrm{W}=$ wavelength of $50 \%$ amplitude response of Gaussian filter used to smooth series (“1” indicates unsmoothed series.

aExtreme reconstructed discharge in calibration period (1937-2009) and prior to start of calibration period (1705-1936).

${ }^{c}$ Number of discrete (see Data and Methods) lows or highs in 1705-1936 more extreme than any in 1937-2009. 


\section{Figure captions}

Fig. 1. Map of study area. Inset shows locations of 11 tree-ring sites numbered as in Table 2. Headwaters of the Ob River main stem are in Russia. The headwaters of the Irtysh River are in Kazakhstan and China. Tree-ring sites are along lower Ob River. Gaged flow record reconstructed is at Salekhard, upstream of the mouth of the Ob River where it enters the Kara Sea. Muzhi and Oktyabrskoe (inset map) are rural settlements with precipitation and temperature records used in correlation analysis.

Fig. 2. Mean monthly hydrograph of Ob River at Salekhard. Analysis period 1936-2009.

Distributions for individual months are displayed as box plots with a horizontal line at the median, a box over the interquartile range, and plus signs at values more than 1.5 times the interquartile range above or below the box. If there are no such outliers, the brackets mark the data extremes.

Fig. 3. Climogram from station Muzhi, Russia. A) Monthly precipitation, 1932-1988. B) Monthly mean temperature, 1932-1990. Distributions of monthly data are summarized by boxplots, as defined in the caption to Figure 2. The mean annual precipitation at Muzhi is $479 \mathrm{~mm}$, and the mean annual temperature is $-4.7^{\circ} \mathrm{C}$. 
Fig. 4. Monthly and seasonal correlations of tree-ring PC1 with climate data for Muzhi. Output from program Seascorr shows correlations of PC1 with temperature (T-top) and partial correlations with precipitation (P-bottom). Results shown for "seasons” of length 1, 3, 8 and 12 months with variable ending month. Significance estimated by Monte Carlo method (Meko et al. 2011) is color coded for two $\alpha$ levels.

Fig. 5. Bar chart of correlations of monthly discharge of Ob River with monthly mean air temperature at Muzhi. Station Muzhy is in the floodplain of the Ob near the largest group of treering sites. Discharge is for gage at Salekhard. Analysis period 1936-1990. Significance at $<0.05$, $<0.01$, and $<0.001$ marked by 1 , 2, or 3 asterisks. Sample size for assessing significance is reduced to account for significant autocorrelation in the individual series, following Dawdy and Matalas (1964). At most this adjustment in any month is to 48 years from the full sample size of 55 years.

Fig. 6. Seasonal variability of strength of tree-ring signal for discharge. Strength measured by $R^{2}$ for stepwise regression model of discharge averaged over various periods ending with July of the growth year on PCs 1-4 of tree rings. Significance of overall F-level of equation indicated by 3, 2, or 1 asterisks $(\mathrm{p}<0.001, \mathrm{p}<0.01, \mathrm{p}<0.05)$.

Fig. 7. Time plots of observed and reconstructed discharge for 1937-2009 calibration period of reconstruction model. Horizontal line at calibration-period mean. 
Fig. 8. Time plot of reconstructed discharge of Ob River at Salekhard, 1705-2012. Confidence interval (50\%) applies to the unsmoothed reconstruction, which is an annual series of discharge averaged over December-July. Decadal variations are emphasized by Gaussian smoothing (red line). Horizontal line at 12,545 m3/sec marks the mean for the 1937-2009 calibration period. Magenta circles mark the 8 reconstruction years classified as extrapolations.

Fig. 9. Correlation of observed with reconstructed discharge as a function of smoothing. Leftmost point is for the unsmoothed series $\left(R^{2}=0.31\right.$, or $\left.r=0.55\right)$. Other points are for series smoothed with successively broader Gaussian filters, with 50\% frequency response at 5, 10, 15, 20, 25 and 30 years.

Fig. 10. Reconstructed discharge of Ob River at Salekhard by two tree-ring studies. A2016 is from current study, and is December-July average. M2007 is from MacDonald et al. (2007), and is October-September average. A2016 and M2007 also differ in that A2016 is gaged discharge, while M2007 is discharge series adjusted for reservoir operations and other anthropogenic factors. The two respective 1800-1990 means (horizontal lines) are 13,138 m3/sec and 12,642 m3/sec. The two series correlate strongly over their full overlap, 1800-1990 $(r=0.55, p<0.001)$. 